\title{
UNIVERSITYOF
}

FORWARD

THINKING

WESTMINSTER用

WestminsterResearch

http://www.westminster.ac.uk/westminsterresearch

On Site

Beech, N., Clarke, L., Wall, C. and Fitzgerald, I.

This is an accepted manuscript of a book chapter published by Routledge in Industries of Architecture on 19 November 2015, available online:

http://www.routledge.com/9781138946828

The WestminsterResearch online digital archive at the University of Westminster aims to make the research output of the University available to a wider audience. Copyright and Moral Rights remain with the authors and/or copyright owners.

Whilst further distribution of specific materials from within this archive is forbidden, you may freely distribute the URL of WestminsterResearch: ((http://westminsterresearch.wmin.ac.uk/)).

In case of abuse or copyright appearing without permission e-mail repository@westminster.ac.uk 


\section{On Site}

Nick Beech, Linda Clarke, Christine Wall with lan Fitzgerald

Contemporary debates on the transformation of building methods, the structure of the building industry, and the introduction of new technologies (informational, material and structural) in professional literature and in the architectural humanities tend to ignore the realities of work on the construction site. This follows a long history of failure to recognise the importance of workers' experience and knowledge of building as a process by the key professions in the industry (surveyors, architects, engineers and others). The absence of the working process in accounts of historical development is exasperated by abstract reflection on building know-how, categories of expertise, and the structure of the industry, when these are not supported by direct observation and engagement with building work and workers. Key assumptions about the relation between structural and technological changes in the industry and the knowledge, skills, composition, and requirements of the work force can be challenged by paying attention to day to day activities and conditions of site work.

The site visit—once common to most programmes of architectural education-is increasingly restricted to construction and site management education. To provide humanities researchers with an experience of what might be learned from a site visit a workshop was organised at the 'Industries of Architecture' conference. The site visit was hosted and organised by the Mechanical and Electrical (ME) arm of a family-based firm, with a $£ 700 m$ turnover. ME has a turnover of about $£ 170 \mathrm{~m}, £ 8 \mathrm{~m}$ of which is attributable to pre-fabrication. The site visited, a hotel project, is part of a $£ 50 \mathrm{~m}$ project, with ME responsible for about $£ 7 m$, whose main contractor was recently taken over and which is financed not by a group of investors, including the City Council. . There are about 140 working on the site, though, as the workshop took place on a Friday afternoon, the operative workforce had mostly finished. ME employs 40-60 on site, including 12 'sub-trades' (ductwork, electrical etc.) and those present included:

1. The contracts manager with responsibilities for other sites in the area

2. Project manager for mechanical work

3. Project manager for electrical work, responsible for about 20 electricians

4.A former electrician and trainee planner 
The workshop lasted about three hours, and in that time the group of 20 delegates were taken on a tour of the project and then provided a $Q \& A$ in the site office. At the time of our visit, the project was in the process of finishing and fitting out of servicesmajor service ducts and key services were already in place, tiling had begun in a basement level swimming pool.

The director of the architectural firm made much of being a BIM architect and of this being a 'BIM building'. We understood too that BIM was now a verb, 'to bim'. We were shown computer generated BIM drawings available on iPads, which seemed to override any need for paper. Nevertheless, all BIM generated drawings had also been reproduced in standard job drawings, available in racks at the site office. The utility of BIM was illustrated by a hole in the wall to allow for a pipe to go through. It was explained that in the past, the hole would have been cut out of the blockwork, rather than already built into the wall following the drawings. This allowed for a faster transition between structural and fitting out work and the elimination of errors resulting from misreading of instructions, faulty measuring out on site or poor construction skills. It also allowed for a compression of the project programming;numerous fitting and fixing operations could be programmed to occur at the same time, when a traditional procedure would have to programme in a succession of works.

However, it was clear that the hole we were shown did not account for block size, resulting in cutting of blocks to conform to the BIM model. Indeed, it remained unclear whether the resulting hole had been produced any faster, or more accurately, than a standard construction procedure. Further BIM misalignments were in evidence throughout the site, as one would expect on a large project. But it remained unclear whether these were the result of 'BIM clash' (faults generated in the original model due to miscalculation between different professional teams) or due to 'human error' on site. A further product of the concertinaed works programming was increased pressure between sub-trades on site. This resulted when different teams, programmed to conduct work at the same time-in the swimming pool for example, installing lighting, fitting tiles, plastering, wiring, etc.-could not in fact complete work without completion of strict sequencing. Tensions between teams were resolved through on site negotiations-pressure of time and money trumping other concerns. The design teams 
working on a BIM model experienced the same intensification of processing. This resulted in positive and negative reflections-increased pressure, further competition, or better understanding, greater co-operation.

Compression of the works programme was further intensified, and the problems that might occur highlighted, with the larger prefabricated elements of the scheme. Corridors of the upper stories were largely in shell form. However, a small number of rooms - with no windows, doors, glazing, or wiring - already had completely finished bathroom units. These 'pods'-delivered prior to finishing of the exterior concrete face of the building, were prefabricated, delivered and crane lifted into position. However, failure of the firm making bathroom pods (the firm had gone bankrupt) meant that only 20 of the 250 bathroom pods had been delivered. The project would have been brought to a catastrophic halt had the contractor awaited the identification of a suitable manufacturer to draw up, process, manufacture and deliver the remaining pods. Instead, the exterior of the building was completed and traditional bathroom fitting and fixing commenced. As these had to be produced to the same dimensions as the original pods, an experimental bathroom fitting out room - including a prototype metal frame to hold the washbasin-had been welded and hand made to the right dimensions. This all resulted in an extra 6,000 man-hours.

Other parts of the project simply could not be produced to modular dimensions in the first place. An enquiry was made about a workbench in a corridor with a metal vice and tube cutter. This was for cutting modular components which did not fit together. It was explained that, in certain tight situations, it was too expensive to install modular piping and the fitters measured the space and cut and fixed the pipe to fit-neither a result of 'BIM clash' nor 'human error'. This was indicative of the processes of production on a construction site that cannot be resolved through off-site planning and conception, but only through the construction process itself.

There was evidence too of the highly skilled individuals required to fit and fix standardised components. Every member of an entire complex of interlocking copper service pipes in the main basement control room was labelled with felt tip initials. All fitters are required to initial these joints, prior to lagging, so that if any subsequent fault or error is identified-by regular inspection on the job or subsequently in use-that fault can be traced to the worker who installed it. And, whilst much was made of a possible 
future in which operatives would walk about with tablets containing the BIM model, evidence on this project was of a network of communication already occurring between operatives: text, dimensions, sketches, were evident in handwritten notices across walls, floors, and form work. These were written in a range of languages-English, East European and possibly Punjabi (this remained unconfirmed). The evidence indicates that contemporary advances in information technology and the new structures of prefabrication and site contracting relied upon-and in crisis situations depended upon-traditional skills and communication of the building operatives.

Nevertheless, there were no apprentices on this site, though SES do have apprentices, who also go to a College of Building. Nowadays apprentices tend to be referred by the local authority and allocated via Section 106 'local labour' clauses, and include those who have already studied full-time in Further Education and need the necessary work experience to complete. This appears as an appropriate solution to the problem of of employer disengagement with apprenticeships and vocational education and training in general, though the training lasts altogether 4-5 years. These young local people are given site experience with a qualified tradesperson acting as mentor, though there is no in-firm training of mentors. The main contractor does not have an operative workforce at all but is essentially a contract manager responsible for the building workforce subcontractors, whose workforce is in turn composed of approximately $60 \%$ East European migrants.. One of the noticeable developments identified in discussion with $\mathrm{ME}$, which employs approximately 40 people, is that is composed increasingly of a supervisory team, the majority of whom have come through 'the tools' rather than through 'education'. The workforce is with the trade union UNITE.

Queries as to how cost was estimated for the project revealed the current distribution of risk. This had been almost entirely transferred from the client to the contractor, a key feature of the 'Design and Build' contract under which the project was operated. In fact, the architectural firm had originally been employed by the client, though has now been brought under the contractor.

The architect described how the architectural workforce of 100 people all use BIM after three months of training and that some of their practice struggled a lot with this. No traditional drafting is done by the practice, certainly not for this project. They have been using BIM for 8 years and it was first trialled 6 years ago and tested for 2 years. They 
have found it to be extremely cost-efficient for the firm, 1200 hours was saved with an 8-storey building, and it has improved co-ordination on site. The architect has all information from subcontractors uploaded into BIM. All site visits and meetings between the design team and the construction team are conducted through the BIM model using a combination of iPads and the printouts in the site office. The result for the project planning as a whole represents a massive 'front loading' of the project. The RIBA Plan of Work 'Stages' 2-4 (from concept design, through developed design, to technical design) are, in essence, a single stage. But this single stage is significantly increased as the architectural team attempt to build a virtual model, by BIM, of the eventual building. The intention is that stage 5 (construction) is supposed to be shorter. All of this is intimately bound up with the issue of risk allocation-as the contractor takes on all the risk, the elimination of costly errors in production become increasingly onerous.

There are a large number of questions that arise from this brief site visit. We adumbrate a few here that might be engaged by humanities and social science researchers. A project such as the Stephenson Quarter development raises serious questions about the impact of new forms of financing and investment in building. The structure of the developer (a mix of private and public investment) retains some benefits-such as the inclusion of Section 106 in the contract-but it increases the adoption of risk allocation to the contractor. That in turn increases Design and Build contracts and the need to generate as much information as possible prior to the construction project itself. This would seem natural to the professions, but it raises necessarily awkward questions for the status and function of the architect (the ethical position of the disinterested professional seems very distant). It also has the paradoxical effect of further distancing the design process from the construction process (the office from the site) and therefore the very knowledge that is needed to produce a production programme that will work to expectation.

$\mathrm{BIM}$, or BIMing, itself appears to hold the most fascination and the most contradictory conditions in all of this. On the one hand a design tool specifically generated to bring about increased collaboration and co-operation between professions, it also appears to increase the fragmentation of knowledge-prefabrication and specialisation but two examples. As a result BIM, or BIMing, itself is, it seems, supposed to produce or be 'knowledge'-the wish image is of a large team of different private professionals 
working in an empty room with Google glasses directly working on the virtual model. The further utopian image is of workers on site doing the same-simply lifting and fitting into place 'matter', the location in space and time given to their vision by the same Google glasses. Wild fantasies and fears need not concern us-it seems highly unlikely that BIM will be able to transcend the need to 'put something on paper' so that people can then translate these, through their understanding and skills, into practice on the construction site. Nevertheless, those design practitioners imagining that the increase in digital design and manufacturing will magically bring them into 'craft' relation with building activity once more, may need to think carefully about what BIMing actually allows the designer to do, know, or even perceive.

The Contract manager ended up by saying—highly sympathetically—that 'we're proud of what we do', emphasising the 'creativity' involved in building work, but that people 'don't understand' this outside the industry because 'we get such bad press'. It is not only the bad press. There is continued pressure-from finance, from professional institutions, and from broader social and material transformations-to 'erase' the worker from the process whilst in fact increasingly resting on his or her skills and abilities. 